\title{
Application of geoinformation systems for a complex analysis of data from agrochemical and soil-erosion monitoring of soils
}

\author{
E.S. Malysheva ${ }^{1,2, *}$ \\ ${ }^{1}$ Belgorod Center for Agrochemical Service, Belgorod, Russian Federation \\ ${ }^{2}$ Belgorod State National Research University, Belgorod, Russian Federation
}

\begin{abstract}
The article describes the development of a geoinformation system module (using the example of GIS "Agroecologist Online") to automate the complex analysis of agrochemical and soil-erosion monitoring data. With the help of an additional GIS module, it allows you to generate reports with tabular data of various groupings: by soil type and degree of erosion; by soil type and slope steepness; by soil type, degree of erosion and exposure; by soil type, slope steepness and exposure; by soil type, degree of erosion, slope steepness and exposure. Based on the presented tables, using the module, it is possible to analyze the indicators of agrochemical and soilerosion survey in a comprehensive manner. The module also allows you to predict the level of yield of certain crops, to timely identify the deterioration of soil resources for a certain territorial unit (within a specific farm, a specific region, as well as on the territory of the entire Russian Federation).
\end{abstract}

\section{Introduction}

In agriculture, soil is one of the main production resources. The agro-ecological state of the soil directly affects the productivity of agricultural crops and the efficiency of the agricultural sector in general. Land protection, maintenance of soil fertility and its rational use are the most important conditions for effective environmental management and territorial planning at all levels of state and society organization. One of the key mechanisms ensuring the implementation of this task is state monitoring of lands, which is understood as a system of measures for monitoring, assessing and forecasting the state and use of lands based on several quantitative and qualitative characteristics, such as acidity, content of organic matter, mobile forms of macro- and microelements, toxic elements [1-4].

The relationship between the agrochemical parameters of the soil and its soil erosion characteristics has been studied by many scientists for a long time [5-16]. However, automatic processing of agrochemical and soil erosion monitoring data is associated with certain difficulties. For example, in order to clearly show the dependence of organic matter content on the erosion degree of a certain soil type, several actions are required:

- $\quad$ select all areas with a certain soil type in the study area (for example, leached chernozems);

\footnotetext{
* Corresponding author: helen2907a@mail.ru
} 
- $\quad$ group the selected areas according to the erosion degree;

- calculate the weighted average organic matter content for each group.

This process requires time and elementary skills from the executor, not to mention how to classify the sites according to additional criteria (exposure and slope angle). Thus, there is a growing need to automate such actions. Geographic information systems (GIS) are commonly used for these purposes.

An integrated approach to the introduction of digital agriculture elements, namely precision farming, allows rationally conducting agrochemical surveys considering soil differences and developing systems of mineral and organic nutrition that increase soil fertility. As a result, there is an increase in the economic and export potential of agriculture. The optimal choice of methods and tools used in the course of soil cover observations, including the performance of statistical observations of changes in soil quality and their imposition on a cartographic basis, will significantly reduce the complexity of this process and the cost of their implementation.

The purpose of the research. To develop a geoinformation system module to automate the complex analysis of agrochemical and soil erosion monitoring data.

\section{Materials and Methods}

The geoinformation system "GIS Agroecologist Online" was developed and implemented in 2017 at the FSBI "CAS "Belgorodsky". It provides users with access to the database of the agrochemical service by clicking on the link on the website http://www.agrochim31.ru [17]. "GIS Agroecologist Online" is protected by patents for a database and the program for electronic computers. Due to the great competition in the market of geographic information systems, programmers need to constantly improve their products, therefore this GIS is developing and new functions for data processing are constantly appearing in it [17-19].

As a part of this study, an additional functionality was introduced into the system, which allows to quickly analyze the data of agrochemical and soil-erosion surveys in the context of working areas and to establish the relationship between the agrochemical parameters of the soil and its soil-erosion characteristics at the lowest cost.

With the help of the additional module "GIS Agroecologist Online" allows to generate reports with tabular data of various groups:

- $\quad$ by type (subtype) of soils and erosion degree;

- $\quad$ by type (subtype) of soils and slope angle;

- $\quad$ by type (subtype) of soils, erosion degree and slope exposure;

- $\quad$ by type (subtype) of soils, angle and exposure of the slope;

- $\quad$ by type (subtype) of soils, erosion degree, angle and exposure of the slope.

\section{Results and Discussion}

When combining databases of agrochemical and soil-erosion surveys, GIS generates a set of agrochemical characteristics for each working contour with a certain type (subtype) of soil, erosion degree, granulometric composition, slope angle and slope exposure. As a result of processing an array of such data, groupings are calculated depending on the specified parameters. Table 1 shows an example of grouping agrochemical indicators by type (subtype) of soil and degree of erosion. 
Table 1. Grouping by type (subtype) of soils and degree of erosion on the territory of the Rovensky district of the Belgorod region.

\begin{tabular}{|l|c|c|c|c|c|}
\hline \multirow{2}{*}{ Erosion degree } & \multirow{2}{*}{ Area, ha } & Mobile forms, mg/kg & \multirow{2}{*}{$\mathbf{p} \mathbf{H}_{\mathbf{H C l}}$} & \multirow{2}{*}{ Organic matter, \% } \\
\cline { 3 - 5 } & & $\mathbf{P}_{\mathbf{2}} \mathbf{O}_{5}$ & $\mathbf{K}_{\mathbf{2}} \mathbf{O}$ & \\
\hline Unwashed & 3684.85 & 100 & 113 & 5.6 & 5.07 \\
\hline Slightly washed & 1487.16 & 97 & 112 & 5.67 & 4.97 \\
\hline \multicolumn{7}{|c|}{ Ordinary chernozems } \\
\hline Unwashed & 25421.15 & 111 & 152 & 6.51 & 5.55 \\
\hline Slightly washed & 11297.46 & 99 & 135 & 6.61 & 5.36 \\
\hline Medium washed & 2224.14 & 80 & 128 & 6.68 & 5.03 \\
\hline
\end{tabular}

Also, it is possible to form a grouping by the type (subtype) of soils and the slope angle in the GIS (Table 2). In this table, the erosion degree is replaced by the slope angle.

Table 2. Grouping by type (subtype) of soils and slope angle on the territory of the Rovensky district of the Belgorod region.

\begin{tabular}{|l|c|c|c|c|c|}
\hline \multirow{2}{*}{ Slope angle } & \multirow{2}{*}{ Area, ha } & \multicolumn{2}{|c|}{ Mobile forms, $\mathbf{m g} / \mathbf{k g}$} & \multirow{2}{*}{$\mathbf{H}_{(\mathbf{H C l})}$} & $\begin{array}{c}\text { Organic matter, } \\
\mathbf{\%}\end{array}$ \\
\cline { 3 - 4 } & & $\mathbf{P}_{2} \mathbf{O}_{5}$ & $\mathbf{\mathbf { K } _ { 2 } \mathbf { O }}$ & & Typical chernozems \\
\hline $0-1^{\circ}$ & 1547.79 & 102 & 113 & 5.59 & 5.05 \\
\hline $1-3^{\circ}$ & 3349.56 & 100 & 113 & 5.63 & 5.04 \\
\hline $3-5^{\circ}$ & 295.33 & 81 & 111 & 5.67 & 5.01 \\
\hline \multicolumn{5}{|c|}{ Ordinary chernozems } \\
\hline $0-1^{\circ}$ & 8784.01 & 115 & 159 & 6.44 & 5.69 \\
\hline $1-3^{\circ}$ & 22293.5 & 106 & 145 & 6.58 & 5.45 \\
\hline $3-5^{\circ}$ & 6907.22 & 94 & 136 & 6.59 & 5.28 \\
\hline $5-7^{\circ}$ & 841.55 & 94 & 131 & 6.67 & 5.16 \\
\hline
\end{tabular}

Using the data presented in Tables 1 and 2, it is possible to build a model of the correspondence degree of soil erosion to the slope angle, as well as to analyze the content of soil nutrients in different areas.

The slope angles are one of the factors determining soil washout, and the degree of erosion manifestation depends on both the angle and the exposure of the slopes (to a greater extent) [16]. Therefore, it is advisable to form such groups by soil types considering the erosion degree, exposure and slope angles at the same time. Such a grouping is more difficult to understand because it considers all the characteristics at once, but at the same time gives much greater opportunities for data analysis. Table 3 shows an example of grouping by soil type, erosion degree, angle and exposure of the slope in the Rovensky district of the Belgorod region. To make the table not too bulky, a part of it showing only ordinary chernozems were taken. The table looks similar for other soil types.

Table 3. Grouping of ordinary chernozems according to the degree of erosion, angle and exposure of slopes on the territory of the Rovensky district of the Belgorod region.

\begin{tabular}{|c|c|c|c|c|c|c|c|c|c|c|c|c|c|c|c|c|c|c|c|c|}
\hline \multirow[b]{3}{*}{ 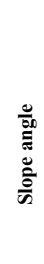 } & \multirow{2}{*}{\multicolumn{4}{|c|}{ Area, ha }} & \multicolumn{8}{|c|}{ Mobile forms, $\mathrm{mg} / \mathrm{kg}$} & \multirow{2}{*}{\multicolumn{4}{|c|}{$\mathbf{p H}_{\text {(HCl) }}$}} & \multirow{2}{*}{\multicolumn{4}{|c|}{ Organic matter, \% }} \\
\hline & & & & & \multicolumn{4}{|c|}{$\mathrm{P}_{2} \mathrm{O}_{5}$} & \multicolumn{4}{|c|}{$\mathrm{K}_{2} \mathrm{O}$} & & & & & & & & \\
\hline & $\overline{8}$ & $\frac{\overline{\widetilde{E}}}{\overline{\bar{z}}}$ & 鸪 & 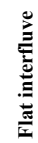 & $\overline{\mathrm{g}}$ & $\begin{array}{l}\bar{\pi} \\
\overline{\underline{z}}\end{array}$ & 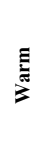 & 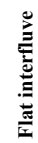 & $\overline{8}$ & 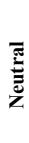 & 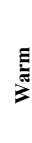 & 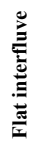 & $\overline{\mathrm{g}}$ & $\begin{array}{l}\overline{\bar{E}} \\
\overline{\bar{z}} \\
\overline{\bar{z}}\end{array}$ & 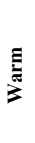 & 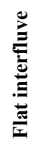 & $\overline{8}$ & 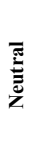 & 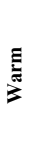 & 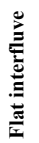 \\
\hline
\end{tabular}




\begin{tabular}{|c|c|c|c|c|c|c|c|c|c|c|c|c|c|c|c|c|c|c|c|c|}
\hline 1 & 2 & 3 & 4 & 5 & 6 & 7 & 8 & 9 & 10 & 11 & 12 & 13 & 14 & 15 & 16 & 17 & 18 & 19 & 20 & 21 \\
\hline \multicolumn{21}{|c|}{ Unwashed } \\
\hline $0-1^{\circ}$ & 2212.1 & 749.04 & 1157.9 & 4622.4 & 102 & 113 & 112 & 123 & 147 & 145 & 144 & 170 & 6.43 & 6.5 & 6.57 & 6.39 & 5.75 & 5.77 & 5.64 & 5.66 \\
\hline $1-3^{\circ}$ & 7662.1 & 3236.9 & 5118.8 & 79.1 & 106 & 108 & 112 & 145 & 148 & 146 & 151 & 168 & 6.54 & 6.57 & 6.56 & 6.44 & \begin{tabular}{|l|}
5.59 \\
\end{tabular} & 5.46 & 5.32 & 5.88 \\
\hline $3-5^{\circ}$ & 339.72 & 86.69 & 142.79 & - & 105 & 111 & 115 & & 152 & 122 & 181 & - & 6.45 & 6.75 & 6.67 & - & 5.69 & 5.48 & 5.11 & - \\
\hline \multicolumn{21}{|c|}{ Slightly washed } \\
\hline $0-1^{\circ}$ & 29.42 & 4.96 & 8.28 & . & 86 & 72 & 60 & - & 171 & 167 & 180 & - & 6.08 & 5.9 & 6.36 & - & 5.76 & 5.7 & 4.04 & - \\
\hline $1-3^{\circ}$ & 2071 & 1160.3 & 2436.2 & - & 105 & \begin{tabular}{|l|}
102 \\
\end{tabular} & 97 & - & \begin{tabular}{|l|}
135 \\
\end{tabular} & 140 & 131 & - & 6.58 & \begin{tabular}{|l|}
6.61 \\
\end{tabular} & \begin{tabular}{|l|}
6.7 \\
\end{tabular} & - & \begin{tabular}{|l|}
5.67 \\
\end{tabular} & \begin{tabular}{|l|l|}
5.49 \\
\end{tabular} & \begin{tabular}{|c|}
5.13 \\
\end{tabular} & - \\
\hline $3-5^{\circ}$ & 2823.7 & 659.04 & 1510.4 & - & 98 & 102 & 95 & - & 129 & 143 & 144 & - & 6.61 & 6.69 & 6.47 & - & 5.5 & 5.27 & 5.04 & - \\
\hline $5-7^{\circ}$ & 447.3 & 41.19 & 35.48 & - & 89 & \begin{tabular}{|l|l|}
156 \\
\end{tabular} & 61 & - & \begin{tabular}{|l|}
127 \\
\end{tabular} & 142 & 139 & - & 6.68 & 6.82 & \begin{tabular}{|l|}
6.43 \\
\end{tabular} & - & 5.31 & \begin{tabular}{|l|l} 
\\
\end{tabular} & 4.95 & - \\
\hline \multicolumn{21}{|c|}{ Medium washed } \\
\hline $1-3^{\circ}$ & 66.28 & 19.06 & 443.84 & - & 117 & \begin{tabular}{|l|}
88 \\
\end{tabular} & 76 & - & \begin{tabular}{|l|}
129 \\
\end{tabular} & 108 & 122 & - & 6.75 & \begin{tabular}{|l}
6.64 \\
\end{tabular} & 6.8 & - & \begin{tabular}{|l|}
5.54 \\
\end{tabular} & 5.42 & \begin{tabular}{|l|}
5.16 \\
\end{tabular} & - \\
\hline $3-5^{\circ}$ & 189.26 & 173.22 & 982.46 & - & 88 & 88 & 71 & - & 126 & 115 & 131 & - & 6.66 & 6.87 & 6.6 & - & 5.18 & 5.25 & 4.88 & - \\
\hline $5-7^{\circ}$ & 105.97 & 29.25 & 174.44 & - & 119 & \begin{tabular}{|l|}
70 \\
\end{tabular} & 87 & - & \begin{tabular}{|l|}
140 \\
\end{tabular} & 103 & 142 & - & \begin{tabular}{|l|l|}
6.61 \\
\end{tabular} & 7.03 & \begin{tabular}{|l|}
6.66 \\
\end{tabular} & - & \begin{tabular}{|l|l|}
5.14 \\
\end{tabular} & 5.24 & \begin{tabular}{|l|}
4.81 \\
\end{tabular} & - \\
\hline
\end{tabular}

Grouping in such a table classifies the soils according to the type and degree of erosion, after which a division occurs according to the angle and exposure of the slope. It can be seen from the table that a large area of unwashed chernozems falls on slopes of cool exposure with a slope angle from 0 to $3^{\circ}$, slightly washed chernozems - almost equally on slopes of cool and warm exposure with a slope angle from 1 to $5^{\circ}$, medium-washed chernozems - on warm exposure slopes with a slope angle from 3 to $7^{\circ}$. In turn, the content of mobile forms of phosphorus and potassium does not express a definite tendency, since they are influenced by the amount of applied mineral and organic fertilizers and the cultivated crop. These rates may change during the field season. With an increase in the slope angle, the $\mathrm{pH}$ value tends to increase slightly. A significant decrease in the content of organic matter down the slope was found for both warm and cool slopes.

\section{Conclusion}

The presented results are generated in GIS automatically and do not require complex manual calculations, which greatly facilitates the processing of large data arrays, as well as their further analysis by specialists. The results obtained make it possible to trace the tendencies of soil degradation or improvement within the administrative districts. Based on such a comprehensive analysis, recommendations are made for the rational use of land resources, fertilizers' application, the introduction of various soil cultivation systems. The article provides an example of data processing for the Rovensky district of the Belgorod region; however, similar calculations can be made for any region, which makes it possible for a comprehensive analysis of soil resources in Russia.

\section{References}

1. S.V. Lukin, Eurasian Soil Science, 50(11), 1323-1331 DOI: $10.1134 /$ S1064229317110096.

2. S.V. Lukin, S.V. Selyukova, Eurasian Soil Science, 51(12), 1547-1553 (2018) DOI: $10.1134 / \mathrm{S} 1064229318120074$.

3. S.V. Lukin, S.V. Selyukova, V.A. Chernikov, N.A. Gaitova, Pollution Research, 39(2), 196-201 (2020)

4. S.V. Lukin, D.V. Zhuikov, Eurasian Soil Science, 54(1), 63-71 (2021)

DOI: $10.1134 / \mathrm{S} 1064229321010099$. 
5. V.D. Vasil'evskaya, V.Ya. Grigor'ev, E.Yu. Pogozhev, E.A. Pogozheva, Moscow University Soil Science Bulletin, 2, 18-24 (2011) DOI: 10.3103/S0147687411020074.

6. E.E. Savchenkova, V.A. Solopova, N.N. Rahimova, Bulletin of the Orenburg State University, 10(185), 416-419 (2015).

7. O.P. Yakutina, T.V. Nechaeva, N.V. Smirnova, Plodorodie, 5, 39-42 (2017)

8. T.V. Nechaeva, N.V. Smirnova, N.V. Gopp, O.A. Savenkov, Plodorodie, 2, 2-5 (2017)

9. G.P. Glazunov, N.V. Afonchenko, V.V. Dvoinykh, Achievements of Science and Technology of AICis, 34, 10-18 (2020) DOI: 10.24411/0235-2451-2020-10702.

10. G.M. Deriglazova, Bulletin of the Kursk State Agricultural Academy, 3, 34-36 (2013)

11. Y.G. Pivovarova, Y.V. Konontseva, J.G. Khludentsov, Bulletin of Altai State Agricultural University, 3, 61-69 (2020)

12. Y.U. Bauer, Ya. R. Reingard, T.A. Ivleva, The Journal Omsk Scientific Bulletin, 2, 173176 (2015)

13. N.E. Zavyalova, Plodorodie, 3, 2-4 (2018) DOI: 10.25680/S19948603.2018.102.01.

14. E.V. Leonicheva, T.A. Roeva, L.I. Leonteva, O.A. Vetrova, Contemporary horticulture, 3, 70-75 (2015)

15. V.D. Zhukov, M.V. Sidorenko, A.Yu. Perov, Moscow journal, 2, 36-45 (2020) DOI: 10.24411/2413-046X-2020-10082.

16. N.V. Sobol, I.M. Gabbasova, M.A. Komissarov, Eurasian Soil Science, 50(9), 10981104 (2017) DOI: 10.1134/S106422931709006X.

17. I.G. Kostin, Zemledelie, 7, 45-48 (2018) DOI: 10.24411/0044-3913-2018-10713.

18. I.G. Kostin, E.S. Malysheva, Bulletin of Kazan State Agrarian University, 2(58), 96-101 (2020) DOI: 10.12737/2073-0462-2020-96-101.

19. E.S. Malysheva, I.G. Kostin, R.M. Khizhnyak, International Agricultural Journal, 64(2), 14-19 (2021) DOI: 10.24412/2587-6740-2021-2-14-19. 